\title{
Creencias, percepciones y experiencias en sexualidad de adolescentes chilenos con infección por VIH adquirida por transmisión vertical
}

\author{
Valeska Vergês H. ${ }^{1}$, Ana Chávez P. ${ }^{2}$, Carolina González H. ${ }^{3}$, Paola Pacheco L. ${ }^{4}$ y Rocío Gómez V. ${ }^{5}$
}

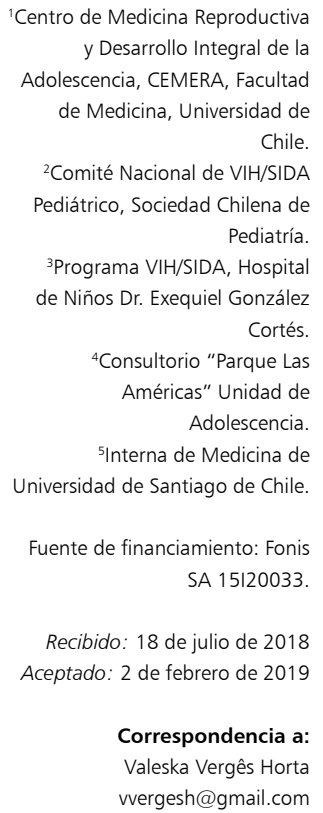

Correspondencia a: Valeska Vergês Horta vvergesh@gmail.com

\section{Introducción}

$\mathrm{E}$ 1 virus de inmunodeficiencia humana (VIH) apareció como infección en el mundo en la década de los 80. A fines de 2016, habían adquirido la infección 36,7 millones de personas y durante ese año hubo 1,8 millones de nuevas infecciones. Entre los años 2010 y 2016 se observó una disminución de nuevas infecciones en adultos de alrededor de $11 \%{ }^{1}$.

En Chile, la situación ha sido diferente, pues la tasa anual de casos confirmados experimentó una tendencia al alza desde el año 2010 (21,4 casos por 100.000 habitantes $\geq 13$ años) hasta el 2015 ( 27,7 casos por 100.000 habitantes $\geq 13$ años). Esto también se observó en el grupo de jóvenes mayores de 13 y bajo 20 años, donde la tasa aumentó de 6,8 por 100.000 habitantes el año 2010 a 9,8 el año 2015. Este grupo etario representa 4,5\% de los casos confirmados de infección por VIH durante ese quinquenio ${ }^{2}$.

En los niños bajo 13 años de edad, desde 1987 a diciembre de 2017 se diagnosticaron 422 casos de infección por VIH, de los cuales $90-95 \%$ es debida a transmisión vertical $(\mathrm{TV})^{4}$.

La incorporación de la terapia anti-retroviral (TAR) ha hecho de esta infección una condición crónica que se ca- racteriza por ser una infección multi y trans-generacional al implicar que la mayoría de los pacientes ha experimentado una desintegración paulatina de la familia al tener uno o ambos progenitores con infección por VIH e incluso que ha muerto producto del SIDA; en algunos casos, el niño o adolescente cursa la patología simultáneamente con uno o ambos progenitores, dificultando a éstos el cuidado óptimo del niño o adolescente. En ocasiones la madre, al ser quien transmite el VIH a su hijo, siente culpabilidad e incluso puede ser culpada por la familia ${ }^{5}$. A todo esto, se suma la discriminación y estigmatización social por asociarse a poblaciones de riesgo como homosexuales, personas con adicciones a drogas endovenosas o que ejercen prostitución ${ }^{6}$. Por tal razón, el tema de la condición sero-positiva y la sexualidad de estos niños o adolescentes puede darse en un contexto difícil para ser abordado por los progenitores o cuidadores.

Consideramos también que la adolescencia es una etapa importante por los cambios biológicos, psicológicos y sociales ${ }^{7}$. En esta etapa se vive el despertar sexual y en este período también se incorpora el riesgo de embarazo e infecciones de transmisión sexual (ITS) ${ }^{8}$. La aparición de los temas de sexualidad en el grupo de adolescentes con infección por VIH debe ser abordado como parte de la educación sexual con el propósito de disminuir los 
comportamientos de riesgo y fomentar comportamientos sexuales seguros y saludables 9 . En este aspecto educativo y de contención, los proveedores de salud cumplen un papel importante porque, por una parte, son los que animan y apoyan a los cuidadores para la revelación de la información en el hogar, y por otra, son una fuente de información confiable para los adolescentes ${ }^{10}$.

A raíz de lo expuesto, surge la necesidad de conocer desde los adolescentes que han adquirido el VIH mediante $\mathrm{TV}$, sus experiencias en relación a la sexualidad. Es un tema poco trabajado por los profesionales de salud y que se aborda desde las necesidades de cualquier adolescente en relación a la educación sexual, a pesar de saber que este grupo tiene necesidades específicas que comenzamos a identificar al momento de trabajar la sexualidad con ellos, ya fuese en forma individual o grupal.

El objetivo de este estudio fue explorar las principales creencias, percepciones y experiencias en las dimensiones de sexualidad de los adolescentes que contrajeran el VIH por vía vertical que están bajo control en hospitales de la Región Metropolitana y de la Región de Valparaíso (V Región) de Chile.

\section{Pacientes y Método}

Investigación de tipo cualitativa, con alcance exploratorio y descriptivo. La investigación cualitativa busca conocer la realidad de los participantes a través del estudio de sus experiencias ${ }^{11}$; se refiere, en su amplio sentido, a la investigación que produce datos descriptivos: las propias palabras de las personas, habladas o escritas y la conducta observable ${ }^{12}$. Este tipo de investigación se fundamenta en un proceso inductivo que va de lo particular a lo general ${ }^{13}$.

Si bien los métodos cualitativos tienen relevancia específica para los estudios sociales y psicológicos, han adquirido cada vez mayor importancia en la comprensión de las experiencias, procesos y conductas relacionadas a la utilización de servicios de salud, al constituirse en una experiencia de investigación valiosa y aportadora hacia la comprensión de fenómenos sociales en la atención en salud dando vida a la voz de los actores, para los cuales se elaboran y diseñan políticas, programas y servicios ${ }^{11}$.

El alcance exploratorio tiene como propósito investigar un fenómeno poco conocido, identificando y descubriendo aspectos importantes. En cuanto al alcance descriptivo, nos permite describir y documentar el fenómeno objeto de estudio ${ }^{14}$.

Los participantes fueron los y las adolescentes desde 12 años en adelante con VIH adquirido por trasmisión vertical, que estaban en conocimiento de su diagnóstico, bajo control en los hospitales de Santiago: San Juan de Dios, Roberto del Río, Sótero del Río, San Borja Arriarán, Exequiel González Cortés y de la Región de Valparaíso: Gustavo Fricke.
Para la recolección de datos se utilizó una entrevista en profundidad semi-estructurada, confeccionada con un grupo nominal de expertos en la temática de adolescencia y VIH/SIDA, grabadas en audio en una sesión, desde abril de 2016 a septiembre de 2017. Para la definición de las categorías a explorar y el número de participantes se utilizó el criterio de Saturación Teórica, es decir, la recolección de datos finalizó cuando la información no aportó nuevas categorías. Y el análisis se realizó de acuerdo a la Teoría Fundamentada ${ }^{15}$ contrastando los datos entre los investigadores y los participantes, a través de la reducción progresiva de los datos, por medio de la codificación abierta, de la cual surgieron categorías iniciales, donde se organizaron las categorías en un modelo interrelacionado, alrededor de una categoría central o tema más importante, que se vincula con las demás categorías, agrupadas en categorías de contexto, fundamentos, resultados y consecuencias (Tabla 1). De este proceso emergió un modelo que tratará de explicar el fenómeno de estudio. Se procuró un registro descriptivo de los participantes, que facilitó la transferibilidad de los resultados. Como apoyo para el análisis se utilizó el software Atlas.ti 1.6.0.

Los aspectos éticos de esta investigación consideraron la participación voluntaria, el proceso de consentimiento informado del adolescente mayor de 18 años o del adulto responsable y asentimiento de los participantes bajo 18 años de edad, además de la aprobación del Comité de Ética de la Facultad de Medicina de la Universidad de Chile y de los hospitales que participaron de la investigación.

\section{Resultados}

Se entrevistó a 28 adolescentes que están bajo control en sus respectivos hospitales (Tabla 2) y a cargo de sus padres o familiares en la mayoría de los casos, salvo dos adolescentes que estaban en instituciones de protección (Figura 1). La distribución de variables personales y familiares según edad y sexo de los adolescentes están descritos en la Tabla 3.

Los temas y categorías de los datos analizados en el estudio fueron:

\section{Creencias y percepciones en sexualidad}

Se encontró que el nivel de conocimiento teórico de los adolescentes entrevistados sobre educación sexual es similar al de cualquier adolescente de nuestro país. La información que manejan tiene que ver con los cambios físicos más que con los psicológicos.

Los conocimientos sobre la sexualidad están más asociados a los riesgos que ésta implica. No se encuentran referencias positivas acerca de la sexualidad como el placer sexual. Los derechos sexuales no son conceptos conocidos por los adolescentes y la mayoría no había 
VIH / SIDA

Tabla 1. Categorización de los datos

Tema

1. Creencias en salud sexual y reproductiva

\section{Categoría}

1.1 Conocimiento en sexualidad

1.2 Conocimiento en VIH/SIDA

1.3 Significado del conocimiento

1.4 Maternidad/Paternidad

1.5 Fuente de información

1.6 Temores asociados a sexualidad

1.7 Expectativas en sexualidad

\section{Sub-categoría}

1.1.1. Conceptos teóricos

1.1.2. Percepción de riesgo

1.1.3 Identificación de factores protectores

1.2.1 Conceptos teóricos

1.2.3 Mecanismos de transmisión

1.2.3 Conductas protectoras

1.3.1 Significado personal

1.3.2 Significado para su entorno

1.4.1 Temores

1.4.2 Expectativas

1.5.1 Forma de resolver dudas

1.5.2 Expectativas de talleres de sexualidad
1.7.1 Características de la pareja ideal

1.7.2 Momento de revelación a la pareja

1.7.3 Expresión de la conducta sexual

2.1.1 Conductas sexuales

2.1.2 Mecanismos de protección

2.2.1 Vivencia en relación de pareja

2.2.2 Influencia de la condición en la proyección en pareja

2.2.3 Emociones asociadas a la expresión de la sexualidad

2.3 Significado de condición de infección por VIH en la expresión de la sexualidad

3. Valoración de los servicios de salud en $\quad 3.1$ Experiencias positivas educación sexual

3.2 Experiencias negativas

4. Vivencia de su condición de infección

4.1 Adherencia al tratamiento por $\mathrm{VIH}$

4.2 Develación del diagnóstico

4.1.1 Motivos para abandonar la TAR

4.1.2 Factores motivadores en la adherencia

4.2.1 Secreto de la condición

4.2.2. Conocimiento previo de su condición

4.2.3 Sentimientos asociados a la revelación

4.2.4 Redes de apoyo

\begin{tabular}{lcccc|}
\hline Tabla 2. Descripción de los participantes & & \\
\hline & n mujeres & n hombres & Total \\
Adolescencia inicial (12-14 años) & 3 & 3 & 6 \\
Adolescencia media (15-16 años) & 5 & 8 & 13 \\
Adolescencia tardía (17-19 años) & 7 & 2 & 9
\end{tabular}

escuchado acerca de ellos hasta que se abordaron durante la entrevista.

En cuanto a la percepción de riesgo, los adolescentes refieren tener conciencia acerca de la posibilidad de contagiar a otros, ya sea a sus parejas o a sus hijos. Los

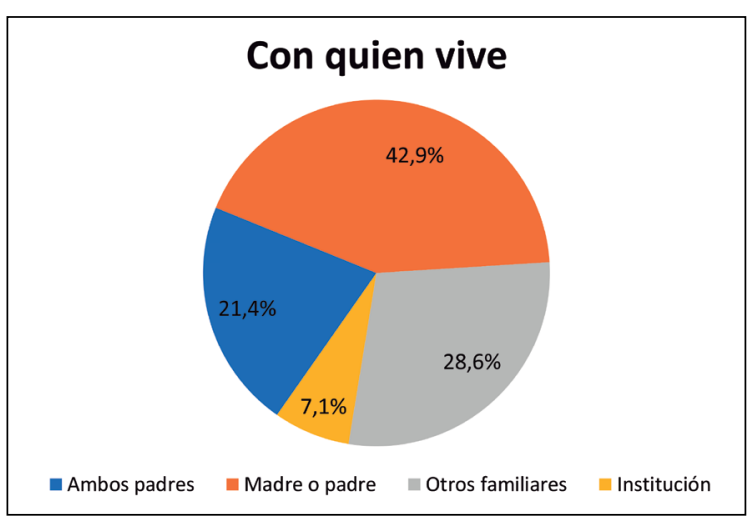

Figura 1. 


\begin{tabular}{|c|c|c|c|c|c|}
\hline \multirow[t]{2}{*}{ Variables } & \multirow[t]{2}{*}{ Categorías } & \multicolumn{2}{|c|}{ Sexo } & \multicolumn{2}{|c|}{ Edad } \\
\hline & & $\begin{array}{c}\text { Femenino } \\
\text { n (\%) }\end{array}$ & $\begin{array}{c}\text { Masculino } \\
\text { n (\%) }\end{array}$ & $\begin{array}{c}12 \text { a } 14 \\
\text { n (\%) }\end{array}$ & $\begin{array}{c}15 \text { a } 23 \\
\text { n (\%) }\end{array}$ \\
\hline \multirow[t]{3}{*}{ Estudia } & Si & $13(86,7)$ & $12(92,3)$ & $6(100)$ & $19(86,4)$ \\
\hline & No & $2(13,3)$ & 0 & 0 & $2(9,1)$ \\
\hline & Deserción & 0 & $1(7,7)$ & 0 & $1(4,5)$ \\
\hline \multirow[t]{2}{*}{ Acompañada/o a la entrevista } & $\mathrm{Si}$ & $15(100)$ & $11(84,6)$ & $6(100)$ & $20(90,9)$ \\
\hline & No & 0 & $2(15,4)$ & 0 & $2(9,1)$ \\
\hline \multirow[t]{2}{*}{ Madre vive actualmente } & $\mathrm{Si}$ & $6(40,0)$ & $8(61,5)$ & $4(66,7)$ & $10(45,4)$ \\
\hline & No & $9(60,0)$ & $5(38,5)$ & $2(33,3)$ & $12(54,6)$ \\
\hline \multirow{2}{*}{ Padre vive actualmente } & $\mathrm{Si}$ & $7 \quad(63,6)$ & $8(72,7)$ & $4 \quad(80,0)$ & $11(64,7)$ \\
\hline & No & $4(36,4)$ & $3(27,3)$ & $1(20,0)$ & $6(35,3)$ \\
\hline
\end{tabular}

factores de riesgo identificados por ellos se relacionan con actividad sexual descuidada, es decir, sin métodos anticonceptivos (MAC), no uso de preservativos, tener muchas parejas sexuales, consumo de sustancia ilícitas y alcohol, y no cumplir con la TAR.

“...el tema del VIH uno... cuando está con una persona no sabe si lo tiene o no, porque no vas a preguntarle "oye, ¿tienes VIH?, tengamos relaciones", no, tampoco buscar una persona con la misma enfermedad, tampoco es prudente, siempre hay que cuidar, si quieres a la persona tienes que cuidarla, pero si no, la puedes contagiar" M033.

Los adolescentes fueron capaces de identificar el uso de anticonceptivos como primera forma de evitar un embarazo. El uso de preservativo se reconoce como anticonceptivo y como la única forma de evitar el contagio de infecciones de transmisión sexual (ITS). La abstinencia no es un concepto incorporado a la sexualidad de estos adolescentes.

$\mathrm{Al}$ indagar en los conocimientos sobre su condición, los participantes identificaron bien el mecanismo de transmisión sexual del VIH, señalándolo incluso como el mecanismo de contagio de sus madres en la mayoría de los casos. Manifestaron, como parte del conocimiento en esta categoría indagada, que la mujer que está infectada con VIH tiene menos riesgo de contagiar que el hombre. Asociaron el riesgo de contagio a la carga viral y al incumplimiento de la TAR. Sin embargo, se observó falta de conocimiento respecto al riesgo de re-infección y al mecanismo de TV ya que tanto hombres como mujeres conocían del riesgo de la lactancia materna, pero la mayoría de los hombres no tenía la misma claridad en relación a la de transmisión durante la gestación y el parto.
En cuanto a la prevención en la transmisión del VIH, tanto por vía vertical como sexual, se hace referencia a la importancia del cumplimiento de la TAR para mantener la carga viral indetectable y de esa manera disminuir el riesgo de contagio a la pareja y/o al hijo.

“...el riesgo más que nada es como... así como hablando médicamente es como no tomar el tratamiento, porque, obviamente hay que tomar pastillas a cierta hora, porque por ejemplo, ya hasta cierta hora ya deja de funcionar, porque las pastillas no, no mata el bicho, sino como que los mantiene dormidos, entonces si el bicho despierta, como que se hace resistente, lo que le llamamos acá, resistencia significa que... el bicho se hace resistente a ese medicamento, entonces cuando uno lo vuelve a tomar, el bicho ya... no le pasa nada, entonces ahi ya, obviamente ... el sistema de la persona ya como que, eh... o sea, es cada vez más grave..." M053.

Acerca del significado de portar el virus, los adolescentes menores mostraron una tendencia a normalizar su condición, restando importancia a lo que pudiera implicar en sus vidas. Esta situación varió en los adolescentes tardíos pues manifestaban que tener el VIH sí les afectaba. Ellos refirieron que al igual que el grupo de menores, en un principio tampoco le dieron importancia a llevar el virus, pero posteriormente, al comprender mejor su situación se dieron cuenta de que sí les afectaba.

Algunos, especialmente los menores, señalaron como principal efecto de tener el VIH, la necesidad de más atenciones en salud refiriéndose a los controles mensuales y a la necesidad de tomar medicamentos diariamente.

“... porque uno... lo que le dije, uno no va a hacer su vida, así como $100 \%$ normal, tiene que venir a médico, 
tomar remedios, parar de... no sé, de hacer algo importante o salir a algún lado y llevar los remedios" H022.

A la mayoría de los adolescentes entrevistados les complicaba la falta de conocimiento acerca del VIH de la población en general y, a raíz de ello, la estigmatización que genera la ignorancia en el tema.

Algunos señalaron que los familiares asocian el VIH a muerte y discriminación. Esta información emergió espontáneamente, pero no fue abordada con todos los jóvenes, por lo que se podría profundizar en un estudio futuro.

En general, los adolescentes atribuyeron al adulto responsable una actitud de sobreprotección en relación a la revelación del diagnóstico, ya que éste se asocia a discriminación.

Frente a la maternidad o paternidad, las mujeres manifestaron temor a contagiar al hijo durante el embarazo. También exteriorizaron temor al proceso de gestación y parto. Algunos manifestaron miedo a ser abandonados por su pareja y a que sus hijos pudieran ser discriminados. Un adolescente expresó temor a contar su diagnóstico a sus futuros hijos. Algunos varones no estaban seguros de si acaso, al padecer la infección por VIH podían ser padres.

"Como lo que le acabo de decir que... que yo, yo por mi parecer no puedo... no pueda tener hijos, porque si puede, si llego a tener hijos poder infectar a la persona y a... y a mi hijo, no" H072.

La fuente de información a la que recurren los adolescentes para resolver sus inquietudes en la temática de sexualidad es la familia en primer lugar, donde se recibe información de los adultos responsables o hermanos y les parece una fuente confiable. También acuden con sus dudas a los amigos y a la pareja.

Dentro de los equipos de salud, la pediatra tratante es una fuente importante y accesible para resolver sus consultas en sexualidad y otras temáticas. Además, varios entrevistados identificaron a los psicólogos/as como personas de confianza y orientadores en relación a las interrogantes que puedan presentar. En el caso de asistir a la atención con profesional matrona, también se identificó a ésta como fuente de información.

En relación a la educación sexual de los establecimientos educacionales, la información que tenían los adolescentes del estudio era escasa y superficial.

Se refirieron también a internet como lugar de consulta, pero paradójicamente, la mayoría de los adolescentes hizo mención a que no es un lugar confiable.

\section{¿Alguien más te ha conversado el tema de sexualidad?}

"Los profesores, mi abuela y la doctora ... La verdad sí, al principio igual me daba... miedo, pero... igual vi, busqué como un poco en internet al principio, pero ya preferi mejor resolver mis dudas con la doctora" M063.

Los adolescentes del estudio consideraron importante que existiera un vínculo de confianza con el adulto, especialmente si es del equipo de salud, para plantear sus inquietudes. También señalaron que es necesario que el espacio físico genere un ambiente de intimidad.

La mayoría de los adolescentes, al inicio de la entrevista consideró que tenía una adecuada información sobre sexualidad, pero al profundizar, reconocieron que les faltaba conocimiento en el tema. En este contexto, coincidieron en la importancia de participar en talleres de educación sexual, donde pudieran compartir experiencias y opiniones con otros adolescentes que padezcan de la infección por VIH.

Varios plantearon la necesidad de educar a la población general sobre VIH-SIDA para evitar la discriminación que, según su opinión, es por falta de conocimiento sobre el tema.

"Porque igual se puede invitar a niños que no lo tienen $y$ darles a informar lo que es la enfermedad, por qué es tan, de repente tan nombrada, en los libros de ciencias y... por qué de repente algunas personas con tan sólo nombrar eso reaccionan mal" M013.

En relación a las características del monitor, este debería ser un profesional bien informado sobre el tema, que inspire confianza, con buen juicio, que sepa escuchar, respetuoso, claro en las explicaciones, directo y con buen humor.

Entre los temas que plantearon para tratar en los talleres estaban:

- Conocimiento sobre VIH-SIDA, Resolución de conflictos en la pareja, Vida sexual en pareja, Revelación del diagnóstico a otros (amigos y pareja), Métodos anticonceptivos, Maternidad/Paternidad, Proyecto de vida.

El temor más frecuente entre los participantes fue el momento de revelar el diagnóstico a la pareja, a no saber elegir el momento oportuno para ello y a la conducta que pueda tener una eventual ex pareja que conozca su condición. También fue recurrente el miedo a transmitir el virus a sus hijos y a la pareja. Algunos de los entrevistados temían a la discriminación por sus amigos al momento de la revelación.

“...obviamente cuando yo tenía que contarle, porque obviamente tenía que decirle, tenía que saber, aunque no hubiéramos... aunque hubiera durado poco la relación o nunca hubiera pasado nada, igual tenía que saber, 
entonces eh... como el temor era... o sea, no como que se alejara de mí, pero... como que ya... fuera algo asi como repugnante para esa persona, algo así como que no te pudiera ver, te tuviera odio... "M053.

"Porque igual vivir con ... como vivir con la sensación de no poder contarle a nadie, que te pueda rechazar, es terrible." H033.

Una entrevistada expresó preocupación por la explicación que tendría que dar a la familia en el caso de ser madre y tener que suspender la lactancia.

También plantearon temor al inicio de la vida sexual $\mathrm{y}$ al posible rechazo de la pareja si le exige uso de preservativo.

Les preocupaba que a pesar de los cuidados que puedan tener, igual contagien a la pareja:

"Que... si la otra persona no está infectada, que yo la pueda infectar y después como que... me odie ya... igual como temor de que me vaya a dejar porque... crea que yo lo voy a contagiar al tiro, o que me sorprenda y que él también tenga lo mismo y por miedo ninguno de los dos sabe" M023.

Los adolescentes, en relación a sus expectativas en sexualidad, manifestaron que una relación debe estar basada en el cariño, aceptación del otro, respeto, compañía y confianza. La mayoría definió como características de una pareja ideal que sea responsable, estudiosa, inteligente, madura y perseverante, sin adicciones y no violenta.

Los participantes que cursaban la etapa inicial de la adolescencia, en su mayoría no se habían planteado tener una relación de pareja, por lo que la revelación del diagnóstico no era considerada un problema para ellos. En cambio, los que han imaginado esta situación, manifestaron en su mayoría que será un momento complicado y consideraban que es importante comunicar su condición antes del inicio de la actividad sexual.

En cuanto al momento de revelar su condición a la pareja, este dependía del tiempo de la relación, de la proyección con la pareja y de la confianza que exista. Pero antes que llegue este momento, consideraron importante que la pareja esté informada sobre el tema de VIH-SIDA. Además, algunos expresaron que ellos mismos deberían capacitarse para aclarar las dudas e interrogantes que probablemente surgirán.

"No, tiene que haber un momento especifico para poder decirle, tiene que haber un... un momento como especial, porque... para mí igual es tema eso, porque sé que de cierta forma la otra persona, no sé cómo va a reaccionar, entonces tengo que buscar el momento y... el momento propicio para poder decirlo” H023.
Los adolescentes declararon lo importarte del acompañamiento y orientación antes y durante la revelación, de preferencia por profesionales que puedan ayudar en las dudas que surjan a la pareja. Coincidieron en sus expectativas al revelar a otros que este debe ser un proceso paulatino, directamente relacionado con la confianza.

Algunos entrevistados preferían guardar el secreto a sus pares porque los consideraban inmaduros y podrían divulgar este secreto a otros.

Los jóvenes manifestaron que antes de revelar el secreto, era importante que el receptor tuviera conocimientos sobre la temática de VIH.

En relación a las expectativas de conductas sexuales en general, ellos se plantearon una postergación de la edad de inicio de la vida sexual, asociado al cumplimiento de metas personales, una mayor madurez psicológica, encontrar la pareja adecuada y tener un tiempo de relación más prolongado que les permitiera un mayor conocimiento entre ellos.

Al proyectarse en el inicio de la vida sexual coincidieron que es importante que la pareja les proporcione confianza y seguridad y a la vez que ellos sientan que están con la pareja adecuada. A pesar del discurso de postergación, ellos plantearon la intención de que su primera relación sexual no fuera algo planificado sino espontáneo.

"Sí, pero... así como planearlo, así como fijar una fecha, una edad, no... no tenemos pensado, yo dije mejor que se dé todo solamente, así como que se dé el lugar, que se dé que estemos solos, que se dé que... o sea, romántico, que se vea bonito, pero... así como planearlo en tal lugar o que... o a esta hora, no, eso no. O sea, como que llegue no más, que se dé” M053.

\section{Experiencias y vivencias}

En relación a las prácticas y conductas sexuales de los entrevistados, la mayoría optó por postergar el inicio de la vida sexual. Seis adolescentes declararon estar en petting 4, es decir, actividad sexual penetrativa: cuatro mujeres y dos hombres. Los varones iniciaron actividad sexual a los 15 años y las mujeres a los 17. Cuatro de los entrevistados estaban en petting 3, es decir, caricias eróticas bajo la ropa incluso con contacto de genitales incluyendo sexo oral, existiendo en este grado de intimidad riesgo de contagio de ITS y riesgo menor de embarazo.

Las conductas de riesgo que se percibieron en relación a las prácticas sexuales, en ambos sexos, fueron el inicio de actividad sexual sin MAC, el uso inconsistente de preservativo y la falta de conocimiento de los riesgos de transmisión de ITS. Además, se pesquisó falta de conducta anticipatoria en relación al uso de los MAC en jóvenes con pareja en petting 3 .

“Es que primero pasó lo que pasó y después... como 
obviamente como si va a empezar esto nos tenemos que cuidar... en el momento pasó y... Es que estábamos en la casa, estábamos viendo películas y... pasó el momento, pasó, es que llegó un momento en que nos quedamos solos. Entonces pasó el momento y... no había nada que hacer" M032.

"Si, o sea, me daba cuenta cuando me iba. Eh... me iba afuera. Me iba afuera, unos minutos antes." H023.

Dos adolescentes hicieron alusión a la mala calidad de los preservativos entregados por el servicio público de acuerdo a sus propias experiencias.

Los adolescentes reconocieron que el preservativo es un buen método para evitar el contagio del VIH y otras ITS a la pareja. Declararon el uso de métodos anticonceptivos como forma eficaz de evitar el embarazo; tres de las mujeres sexualmente activas eran usuarias de métodos hormonales y practicaban, la mayoría de las veces, doble protección, pues refirieron utilizar preservativos casi siempre; sólo una de las adolescentes era usuaria exclusiva de preservativo aludiendo, como razón, que no había sido llevada por el adulto responsable a buscar un MAC a su centro de atención primaria.

En sólo dos de las adolescentes hubo conducta anticipatoria en relación al uso de MAC, es decir, se inició anticoncepción antes del inicio de la actividad sexual.

En el discurso los adolescentes plantearon lo importante que es revelar el diagnóstico a sus parejas antes del inicio de la vida sexual y la mayoría lo hace, pero hubo dos adolescentes que manifestaron haber iniciado sin contar acerca de su condición.

En cuanto a la experiencia en resolver sus dudas, la mayoría de los adolescentes manifestó que fueron acogidas y generalmente aclaradas por el equipo tratante en los servicios de pediatría. La pareja también es considerada al momento de resolver dudas.

Algunos expresaron que percibían en los adultos cierto temor de promover el inicio de la vida sexual al profundizar en la información que entregan.

"O sea, igual yo lo encuentro que es como un tema súper normal, pero... hay veces que uno le pregunta a tal persona y como que... como que le da cosa hablar del tema, o como que dice, no estamos... estás como muy chica, muy pendeja para... para responder, o sea, para que yo le responda, entonces... yo creo que igual esa gente es como que... como que si me cuenta como que... voy a cometer algo malo o algo así, como que... entonces..." M053.

En general, la vivencia en el pololeo es valorada como positiva, incluso al revelar el diagnóstico a la pareja. El tiempo de relación resultó ser un factor importante para decidir contar sobre la condición de infectado con VIH.

Con posterioridad a la revelación y comprensión del significado de tener la infección por VIH por parte de la pareja, la mayoría coincidió en que la relación se fortaleció favoreciendo la confianza y aumentando el apoyo mutuo. La pareja manifestó interés en conocer más sobre la condición de los entrevistados.

"También se preocupó y me empezó a dar consejos, tuvimos charlas...Pero porque él quiso, porque quería saber más del tema... sí, cuidarme...O sea, él no me rechazó" M073.

"O sea... me senti bien, porque él me apoyaba en algo que para mí igual ha sido como una carga durante toda la vida" M043.

La decisión de revelar el diagnóstico a la pareja no significó necesariamente inicio de actividad sexual.

Las redes de apoyo identificadas fueron la familia, amigos, equipo de atención clínica y la pareja en el caso de llevar un tiempo que ellos consideraban suficiente de relación.

En general, los entrevistados relataron sentirse aceptados por los amigos a los que han revelado su condición; sin embargo, tienen temor a la discriminación porque consideran que el desconocimiento del entorno en relación al tema genera rechazo.

"Porque si tienen conocimiento de eso, de lo que es el $V I H$, no creo que haya problemas. Pero si son ignorantes, y que "ay, que te lo pego con la saliva y que aquí y allá". No, mejor que no le cuenten o que no vivan juntos" M033.

En relación con la revelación del diagnóstico a otros, destacaron el beneficio de establecer vínculos importantes con las personas que los han aceptado con su condición, a pesar que esto también les generaba un compromiso hacia estas personas, ya fuese pareja o amigo/a.

“... para entablar algo como serio, no sé, algo así, es que no sé cómo explicarlo, pero es como... como que sé que no cualquier persona me va a respetar por lo que tengo, entonces en esa, en esa forma trato de escoger a la gente que tengo cerca muy bien, como que trato de darle seriedad" H023.

El temor a no ser aceptados socialmente apareció en la mayoría de los participantes en relación a la maternidad o paternidad, al pensar que sus hijos podrían nacer con el VIH y ser discriminados.

Si bien la mayoría tuvo buenas experiencias al revelar su condición a la pareja, en dos casos se produjo rechazo de la familia, específicamente de las madres de 
las parejas que se opusieron a la relación, llegando una de ellas a amenazar con dar a conocer públicamente su condición.

La mayoría de los entrevistados en etapa de adolescencia temprana y media consideraron que la condición de estar infectado con VIH no les influía mayormente en la proyección de vida en pareja, la diferencia que ellos percibían se limitaba sólo a las visitas médicas frecuentes y el cumplimiento de la TAR.

“No, no lo veo tan negativo...No, porque la persona que porta la enfermedad eh... tiene un tratamiento, para que no quede... la otra" H011.

A medida que aumenta la edad y la experiencia sexual de los adolescentes, observamos que la condición influye en la proyección de vida y en la expresión de la sexualidad. Los adolescentes que han tenido la experiencia de vivir una relación de pareja, consideraron que el deseo de ser madre o padre se ve afectado por su condición; incluso dos varones pensaban que no podrían ser padres. También expresaron la necesidad de aumentar el cuidado en la actividad sexual para no contagiar a la pareja lo que genera mayor estrés a la relación.

"Sí...De que no puedo tener, no puedo tener relaciones sin cuidarme. En que no puedo... embarazarme asi de la nada, no más, porque también tengo riesgos” M073.

Los sentimientos asociados a la sexualidad y aludidos por los adolescentes, guardaban relación con el temor al rechazo por parte de la pareja; algunos sentían vergüenza por su condición, incluso uno de los entrevistados contó que le resultaba difícil enamorarse.

"No... me cuesta enamorarme, mucho, por la misma razón, por lo que tengo.

Yprefiero estar ... siempre fría a ... a después (...) como se dice...A empezar una relación, como se dice, pensar con la cabeza y no con el corazón” M063.

“En el colegio ...por ejemplo, la semana pasada vino una señora de... de un hospital que hay, que era ... ¿cómo se llama eso?, que... decía como la prevención de ... como que... nos enseñaba a ocupar el condón y todo eso... Todos, casi todos hicieron preguntas.

Y la señora habló sobre VIH. Eh... sí, y como que ahí yo me sentí como... identificado, pero así...calladito" H032.

\section{Valoración de educación sexual recibida en los Servicios de Salud}

La mayoría de los adolescentes manifestó que hay espacio para conversar en la atención clínica. En relación a la atención psicológica, consideraron que se le da cabida a la pareja en caso que deseen incorporarla.

Sin embargo, algunos expresaron que la falta de un espacio cómodo y privado en un servicio de pediatría, los intimida para conversar temas de sexualidad. También plantearon que el lenguaje que usan los profesionales a veces es poco claro.

\section{Vivencia de la condición de tener la infección por $\mathrm{VIH}$}

Los factores que se describieron como motivadores para tener una adherencia efectiva a la TAR fueron: conocer el diagnóstico, la conciencia de autocuidado del adolescente y el compromiso hacia la pareja que motiva a cuidar del otro a partir de su propio cuidado. En relación a la práctica del autocuidado lo que manifestaron los jóvenes entrevistados es el deseo de sentirse bien y poder cumplir con sus proyectos de vida.

“Es que no se, podría llamarse amor, y lo hago más que nada por amor por ella para no hacerle daño porque yo la quiero... ahí va el afecto porque la amo la quiero cuidar" H013.

Se pudo observar la importancia de la supervisión del adulto responsable, pues los entrevistados supervisados fueron más adherentes, independientemente de la edad.

"Me confundo de nombres, pero me tomo dos en la noche. Pero los... los identifico por los colores. Porque uno es amarillo y el otro es blanco...Entonces siempre mi... mi tata igual me va, me está como... observando en lo que hago, en lo que me tomo" M073.

La mayoría de los adolescentes al momento de pasar a ser los responsables de su tratamiento, suspendieron la terapia por un tiempo variable. Las razones que aludieron fueron: rebeldía provocada por la rabia de tener la infección por VIH, aburrimiento de la TAR, flojera, olvido y por creer que no les pasaría nada al suspender. La mayoría de los entrevistados manifestó que la adherencia se facilitaba cuando los cuidadores los apoyaban en este aspecto, ya fuese insistiendo o recordando el cumplimiento de la terapia.

“A las... una es a las 8 y media y la otra a las nueve y en la mañana también tomo a las... 8 y media. A veces me la tomo solo y a veces me... tienen que recordar" HO21.

Previo a ser informados de su condición, todos los adolescentes sospechaban que algo ocurría en relación a su salud, pero la mayoría no lo relacionó con tener el VIH a pesar que escucharon más de una vez hablar del tema en los controles. Varios adolescentes investigaron acerca 
de su terapia en internet lo que les permitió confirmar sus sospechas; sin embargo, aún no tenían la certeza absoluta de su diagnóstico.

“Eh... sinceramente empecé a... le ponía veía la caja del remedio, le ponía en google, para qué era y ahí como que empecé a sospechar y cuando ya me dijo, yo ya como que cachaba" H042.

La principal fuente revelación de su diagnóstico fueron los adultos responsables; en el caso de los adolescentes que vivían con sus madres fueron ellas las que les revelaron su condición. La edad de revelación en promedio fue alrededor de los doce años. La revelación de tener el virus generó un impacto en la mayoría de los entrevistados, los sentimientos que refirieron fueron, en su mayoría rabia y pena.

“...es que suena feo, suena feo así como uno lo dice. pero lo que se me pasó por el momento, fue así como... que... maldito viejo, fue así como para decirlo bien, maldito viejo, porque... porque mi mamá, mi mamá se fue con mi papá, para Antofagasta...Me dio... me dio rabia con él... Con mi mamá... no sé, sentí que era pava, la sentí pava... vivo con amor pero... como tan pava, tan perna, no sé, pava” M012.

"Como rabia igual... O sea, no, pero... porque igual mi papá contagió a mi mamá y mi mamá me había dicho" HO22.

Posteriormente a la revelación de su diagnóstico, se sintieron apoyados por el equipo de salud, especialmente por el médico tratante y por el profesional psicólogo/a.

En relación al secreto de la condición de tener el virus, fue fomentado por los adultos, motivado por el miedo a la discriminación. Vivir con el secreto les complicaba frente a las personas importantes en su vida porque sentían que no eran sinceros sobre todo con los amigos. Por otra parte, las personas cercanas a ellos notaban que algo sucedía y hacían preguntas.

"Porque como es mi amiga, uno... es que lo que pasa, uno igual se siente... mal al no decirle a la otra persona todos los... todas las cosas, porque realmente ya tu amiga te conoce al derecho y al revés, sabe todas tus cosas..." M063.

La vivencia de contar a otros fue valorada como positiva porque la mayoría se sintió acogido y apoyado; por otra parte, sintieron el alivio de comunicar el secreto de su condición a personas significativas en sus vidas.

\section{Discusión}

Con relación a las creencias en sexualidad, influye la información de tipo general que manejan los adolescentes, centrada básicamente en aspectos negativos de ella como el riesgo de embarazo y de ITS, desconociendo otros ámbitos de la sexualidad como lo relacionado con los derechos sexuales, entre otros. El conocimiento teórico sobre este tema no ha sido profundizado desde una educación sexual sistematizada y adecuada e incluso observamos un conocimiento muy básico sobre las temáticas que fueron abordadas durante la entrevista tales como comportamiento sexual, ITS y MAC.

Se pudo observar falta de conocimiento en relación a su condición de estar infectado con VIH; esto se hizo presente al indagar en conceptos como vías de transmisión, reinfección, y la existencia de mitos en relación a la sexualidad y al VIH. Entre estos mitos se pudo constatar algunos que son frecuentes en la población general, como considerar método anticonceptivo eficaz el coitus interruptus o el mantener relaciones sexuales de pie y el aumento de peso o la infertilidad por el uso de los MAC hormonales. Respecto a la transmisión del VIH muchos aseguraron que las mujeres no pueden transmitir el VIH a sus parejas sexuales.

La familia es considerada una importante fuente de información y primer lugar de consulta. En relación a los equipos de salud, los adolescentes manifiestan que les generan confianza tanto en los conocimientos como en la orientación que reciben de parte de ellos.

En nuestra investigación identificamos algunos factores protectores como:

- Una familia involucrada en el cuidado y proyecto de vida del adolescente que incluye las oportunidades educativas.

- Vínculo de confianza y afectivo con el cuidador y con los profesionales de salud que los atienden.

- Espacios para informarse de la salud sexual y reproductiva.

- Uso de condón y de un método anticonceptivo seguro para el ejercicio de la sexualidad en pareja.

Se observa una necesidad de normalizar su condición lo que muchas veces puede enmascarar dificultades para aceptar su seropositividad e impide visualizar conductas que se traducirán en un mejor pronóstico como es la adherencia a la TAR y conductas de autocuidado en la expresión de su sexualidad. En este sentido, es importante el acompañamiento y apoyo terapéutico en estos jóvenes desde pequeños, para ayudarles a procesar emocionalmente esta condición y poder ayudarlos a integrarla a su identidad.

Dentro de los temores de vivir su sexualidad destaca el miedo a transmitir el virus a otra persona, ya sea a la 
pareja o a los hijos, temores que influyen en la proyección de maternidad o paternidad. Es necesario abordar esta temática con ellos, proporcionado conocimientos y herramientas que les permitan proyectarse, pero cuidando de su salud y la de su pareja y los futuros hijos ${ }^{16,17}$.

En nuestro país, $48 \%$ de los jóvenes bajo 20 años de edad, se encuentra sexualmente activo; los adolescentes entre 15 y 19 años tienen una edad promedio de iniciación sexual de 15,4 años ${ }^{18}$. En el grupo de estudio, 22 participantes estaban en la etapa de adolescencia media y tardía, de los cuales $27 \%$ había iniciado vida sexual, con un promedio de edad de comienzo de 16 años. Si bien la edad de inicio no dista significativamente de las estadísticas nacionales, la mayoría en este grupo ha optado por postergar el inicio de vida sexual. La explicación frente a esta postergación se puede encontrar en el temor que les genera hablar del tema, el temor al contagio de la pareja y al constante acompañamiento y apoyo de un adulto en la etapa de la adolescencia que no necesariamente es un familiar, pudiendo ser profesionales del equipo de salud, dando pautas de comportamiento sexual que les ayuda a ser más precavidos en la expresión de la sexualidad.

En relación a la conducta sexual, hay que considerar que, si bien los adolescentes saben que deben protegerse usando MAC, la impulsividad propia de su edad muchas veces les impide tener conductas responsables. En este sentido, es importante que tanto la familia como el equipo de salud conozca y de cuenta de las señales que pudieran prever un inicio de actividad sexual, tomando medidas como son la educación, la consejería y el inicio de MAC. Se entiende que los jóvenes quieran disfrutar de una sexualidad espontánea considerando esta actitud sana emocionalmente; sin embargo, es importante entregar información y educación antes, para que estén preparados cuando este momento ocurra.

Si se pesquisa que un adolescente está en riesgo de embarazo, el médico tratante debe considerarlo una situación de urgencia y ofrecer inicio de MAC de inmediato. Por ello surge la necesidad de entregar información en la temática a los profesionales, pero con una perspectiva que aborde los requerimientos especiales de este grupo como son el resolver dudas sobre la expresión de la sexualidad y los conocimientos sobre VIH-SIDA.

El deseo de inicio de vida sexual puede ser una motivación para cumplir con la terapia, ya que todos refieren temor a contagiar a su pareja y esto los motiva al autocuidado. Esta necesidad de proteger a la pareja favorece la adherencia a la TAR.

Tanto en la educación como en la motivación para la adherencia a la terapia es fundamental, según refieren ellos, que exista el apoyo de un adulto significativo, teniendo presente que la autonomía progresiva es un proceso que debe ser acompañado por el cuidador hasta que se logre la conciencia de auto-cuidado. Esto es muy importante de considerar porque algunos adolescentes relatan que los adultos los dejan solos en el tratamiento, argumentando que ya están en edad de ser responsables. La sugerencia es que se mantenga el acompañamiento, recordando y supervisando el cumplimiento de la TAR durante la adolescencia media y tardía ya que los motivos que dieron los entrevistados para suspender la terapia en este período, fueron aburrimiento, rebeldía o por creer que el abandono en la TAR no tendría efecto sobre su salud.

El ser portador de VIH, al estar asociado a la estigmatización, discriminación y a la idea de muerte, que los participantes atribuyen a la ignorancia de la población en relación al VIH-SIDA, es una condición que se debe ocultar; el estigma en sí puede conducir a sentimientos de vergüenza, culpa y aislamiento ${ }^{19}$. Por todas estas razones es que esta condición se transforma en un gran secreto familiar tan potente que se convierte en un tema tabú, incluso entre las personas que manejan la información del diagnóstico del adolescente, impidiendo el accionar de redes de apoyo. Esto genera angustia en los niños y adolescentes que crecen ocultando esta condición a sus cercanos. Un estudio realizado en adolescentes en SudÁfrica, muestra que más de $95 \%$ de los adolescentes que creció con la infección por VIH, pensaba que la divulgación a la familia ayudaría en la adherencia a la atención médica y esta, a su vez, en la adherencia a la terapia ${ }^{20}$. Conocer el diagnóstico les permite responsabilizarse progresivamente de su pronóstico y calidad de vida ${ }^{21}$. Por esta razón planteamos el trabajo con el adulto a cargo para abrir el tema en el círculo que rodea al adolescente en el ambiente familiar y social.

Por otro lado, el tema de la estigmatización y discriminación que se da en nuestra sociedad se transforma en una barrera para la prevención del contagio de VIH, pues las personas en general, lo asocian a características tales como homosexualidad, sexualidad descuidada y consumo de drogas. De esta manera no se logra visualizar la posibilidad de contagio.

Con relación al momento de develación del diagnóstico, los participantes, en su mayoría, sospechaban que algo ocurría con su salud desde pequeños y al momento de comunicarles el diagnóstico sólo encontraron confirmación de lo que ya sospechaban. Recomendamos por esta razón iniciar la develación a los niños en cuanto empiezan a preguntar, no como un momento único sino como un proceso adaptado a la necesidad de cada niño, entregando información apropiada a la edad y quitarle, al momento de revelar, la carga negativa que conlleva ${ }^{21}$. De esta manera, podremos evitar la angustia de no saber el diagnóstico y también evitar la revelación no planificada y en muchos casos inadecuada. La literatura define la "Develación" como un proceso complejo y de prolongado reconocimiento donde van descubriendo a través 
de sucesivas aproximaciones e interacciones con otros, el significado de haber adquirido la infección por $\mathrm{VIH}^{22}$.

Considerando lo gratificante que resultó a los participantes revelar el diagnóstico a su círculo cercano (amigos y pareja), recomendamos entregar conocimientos puntuales en respuesta a las dudas que puedan surgir en el momento de la revelación, además del acompañamiento y contención emocional para facilitar este proceso. El equipo de salud debería considerar la consejería de manera sistematizada, lo que fue planteado por los mismos adolescentes. De lo observado en esta investigación, los participantes tienen parámetros que les permiten escoger a las personas a quienes revelarán su condición, que sería interesante poder identificar en próximas investigaciones; destaca el tiempo que llevan de amistad o de relación de pareja, que les da la confianza necesaria para contar sobre su condición.

La revelación a la pareja resulta más compleja porque tiene otros componentes directamente relacionados con la expresión de la sexualidad. Este proceso requiere necesariamente acompañar al adolescente en la toma de decisión de revelar su condición, orientar en la elección del momento adecuado para hacerlo y la forma en cómo revelarlo.

Es fundamental empoderarlos en su capacidad de decisión sobre la expresión de su sexualidad en términos de derechos sexuales y reproductivos y, por otra parte, comprender que la pareja también tiene el derecho a tomar una decisión estando debidamente informado de la situación de VIH.

A raíz de lo encontrado en esta investigación recomendamos para la población de niños y adolescentes con VIH, complementar un programa de educación sexual con medidas específicas que incluya prevención del contagio a otros, contención de pares y la educación en su patología, fomentando el auto-cuidado; esto último aplicable a todas las condiciones crónicas, incorporando a la familia y al equipo de salud.

Dentro de los establecimientos de Salud, los adolescentes solicitaron espacios protegidos que permitan hablar el tema de sexualidad de forma individual y grupal. Esto está de acuerdo con otras experiencias con adolescentes que han crecido con la infección por VIH, en las que también han solicitado, al igual que los participantes de nuestro estudio, espacios de apoyo y consejería y servicios de salud sexual ${ }^{21}$. Desde esta observación, es importante brindar un espacio que garantice la privacidad para explorar la etapa del desarrollo sexual del adolescente permitiendo la consejería en sexualidad adecuada que fomente la reflexión en un ambiente de confidencialidad, sin el adulto a cargo. Esto especialmente considerando que es una atención que se da en un servicio de pediatría, donde se acostumbra a incorporar al adulto responsable.

La necesidad manifestada por el grupo de conocer a otros adolescentes que viven en igual condición, se traduce en un beneficio para ellos por ser una instancia de compartir experiencias con pares, evidenciando que no son los únicos en su situación. En una investigación que buscaba indagar en la divulgación del diagnóstico a adolescentes infectados por vía vertical, se demostró que una forma de llenar el vacío de conocimiento fue usando la información recolectada de sus compañeros con infección por VIH. Los adolescentes más experimentados usaron terminología apropiada para explicar conceptos importantes del VIH / SIDA en comparación a aquellos que recientemente habían sido informados sobre su estado. La práctica de trabajar en grupo, tanto por el equipo de salud como por los adolescentes, fue considerada importante por el apoyo mutuo que significó entre los jóvenes en el proceso ${ }^{20}$.

Se sugiere idear estrategias por parte del equipo de salud, que les permita a los niños y adolescentes disminuir la inasistencia a sus actividades académicas y al mismo tiempo cumplir con sus controles. Las reiteradas ausencias despiertan curiosidad en su entorno, que se puede traducir en la necesidad de mentir, lo cual genera que algunos desarrollen, de manera silenciosa, un sentido de vergüenza acerca de su enfermedad y sobre lo que ocurre en sus cuerpos $^{23}$. En cuanto a las situaciones de discriminación es importante que el personal de salud pueda detectarlas y apoyar tanto emocional como legalmente a los afectados.

Frente a la inquietud que genera la estigmatización y discriminación, sería fundamental incorporar en la educación sexual de la población general una mirada de aceptación frente a las personas que tienen la infección por VIH. Si bien el objetivo principal es fomentar la prevención del contagio, el aumento de personas seropositivas en nuestro país (grupo de riesgo más afectado es entre los 15 y 25 años) aumenta la posibilidad de encontrarse en una relación sero-discordante. Educar sobre la condición de infección por VIH a la población general, en opinión de los entrevistados, disminuirá la estigmatización y discriminación.

\section{Recomendaciones}

Surgen las siguientes recomendaciones de esta investigación como aporte para el abordaje de la sexualidad en este grupo de adolescentes:

- Capacitación permanente a la familia, al niño y adolescente implantando un programa de educación sexual en los servicios pediátricos.

- Capacitar a los equipos tratantes en salud sexual y reproductiva del adolescente. Como producto de esta investigación se elaboró una guía práctica para el equipo de atención "Recomendaciones y orientaciones técnicas para el abordaje de la sexualidad en 
adolescentes que viven con VIH" que fue entregada a los encargados del VIH pediátrico de cada hospital, disponible en el Comité Nacional de SIDA Pediátrico.

- Coordinación efectiva con ginecología para facilitar la derivación oportuna del adolescente que requiera anticoncepción.

- Atenciones clínicas flexibles en los servicios de salud que resguarden la privacidad de los adolescentes con infección por VIH disminuyendo la inasistencia a sus actividades académicas.

- Implementación y ejecución de talleres educativos, donde se pueda incorporar como monitores a jóvenes con infección por VIH de mayor experiencia como apoyo a los profesionales.

- Implementación de espacios de consejería individual en Salud Sexual y Reproductiva para adolescentes garantizando la privacidad de la atención.

- Disponibilidad de preservativos en los servicios pediátricos para los adolescentes que lo requieran. En particular en este grupo recomendamos tener variedad de preservativos para fomentar el uso consistente de éste.

- Si bien nuestro país carece de formalidad en la educación sexual en los establecimientos educacionales, se recomienda al ministerio de educación la necesidad de abordar el tema de VIH/SIDA como parte de la inclusión.

- Fomentar la educación sexual en esta patología a la población en general.

\section{Conclusión}

Los niños y jóvenes afectados por la infección de VIH, a diferencia de otras patologías crónicas, experimentan gran dolor emocional, no sólo por la pérdida de uno o ambos padres, sino por llevar el estigma de una enfermedad que, aún en la actualidad, se asocia con promiscuidad, descuido e irresponsabilidad, todos adjetivos con carga negativa.

Favorecer el desarrollo de un proyecto de vida similar al de cualquier joven libre de esta condición es un gran desafío como sociedad, que permitiría en cierta forma una reparación del dolor que genera heredar esta condición de salud.

\section{Resumen}

Introducción: Desde la incorporación de la terapia anti-retroviral (TAR) la infección por VIH ha pasado a ser una condición crónica, mejorando la sobrevida y permitiendo que los niños que han sido infectados con el virus lleguen en mejores condiciones a la adolescencia, donde se ven enfrentados a una serie de cambios, entre ellos, al despertar sexual. Objetivo: Explorar las principales creencias, percepciones y experiencias en sexualidad de un grupo de adolescentes con infección por VIH adquirida por transmisión vertical. Pacientes y Métodos: Se realizó una investigación cualitativa con alcance exploratorio y descriptivo. Se aplicaron entrevistas semiestructuradas a 28 adolescentes, bajo control en hospitales de Santiago y Región de Valparaíso, con infección por VIH. El análisis se realizó de acuerdo a la Teoría Fundamentada. Resultados: Se observó falta de educación sexual y una visión que se centra en los riesgos, tales como contagio de infecciones de transmisión sexual o embarazo adolescente. Existen temores frente a la posibilidad de rechazo de los otros y a transmitir el virus a la pareja o a los hijos y los invaden sentimientos de vergüenza y rabia. Conclusión: Es importante capacitar a los profesionales de salud que trabajan con este grupo, pues son identificados como fuente confiable de información y educación.

\section{Referencias bibliográficas}

1.- UNAIDS. Hoja informativa-Últimas estadísticas sobre el estado de la epidemia de sida. Disponible en: http://www.unaids.org/es/ resources/fact-sheet.

2.- ISP: Ministerio de Salud. Santiago: Instituto de Salud Pública; c2010-2015. Boletín Vigilancia de Laboratorio: Resultados confirmación de infección por VIH en Chile; 2017 Mar 10 [Citado 2018]. Disponible en: http://www.ispch. cl/sites/default/files/BoletinVIH-15112017A. pdf.

3.- Wu E, Galaz M, Larrañaga C, Chávez A, González M, et al. Infección por VIH/SIDA en niños y adolescentes: cohorte chilena 1987-2014. Rev Chilena Infectol 2016; 33:
11-19. http://dx.doi.org/10.4067/S071610182016000700002.

4.- Beltrán C, Afani A. La pandemia VIH/SIDA y las metas 90/90/90. En Sepúlveda C y Afani

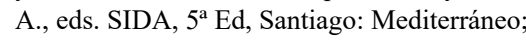
2017, p.18-32.

5.- Close K. Psychosocial aspects of HIV/AIDS children and adolescent. Anabwani G, Calles N, Chang Pitter J, Close K, Ferrer K, Ferris M, et al. HIV Curriculum for the Health Professional, 1 st Ed. Houston: Baylor College of Medicine. 2006, p 319-31.

6.- Rubinstein E. Abordaje clínico de adolescentes con VIH. E: Adaszko A, Caillaud A, Asís S, Barboni L, Bouzas G, Belforte M, et al. Atención Integral en niños, niñas y adolescentes con VIH, 1ra ed. Buenos Aires: Fondo de las
Naciones Unidas para la Infancia. 2012, p. 235 47. https://www.sap.org.ar/uploads/consensos/ gu-iacuteas-de-quot-atenci-oacuten-integral-deni-ntildeos-ni-ntildeas-y-adolescentes-con-vih. pdf.

7.- Suárez B y Zubarew T. Desarrollo psicológico y social del adolescente. En Zubarew T, Romero M y Poblete F., eds. Adolescencia promoción, prevención y atención de salud, 1ra ed. Santiago: Ediciones Universidad Católica de Chile; 2003, p. 33-40.

8.- Bardi L. Desarrollo psicológico e identidad sexual. En Molina R, Sandoval J y González E, eds. Salud Sexual y Reproductiva en la Adolescencia, 1ra ed. Santiago: Mediterráneo; 2003, p 16-22.

9.- Vranda M, Mothi S. Psychosocial issues 
of children infected with HIV/AIDS. Indian J Psychol Med 2013; 35: 19-22. doi: 10.4103/0253-7176.112195.

10.- Kidia K K, Mupambireyi Z, Cluver L, Ndhlovu CE, Borok M y Ferrand RA. HIV Status Disclosure to perinatally-infected adolescents in Zimbabwe: a qualitative study of adolescent and healthcare worker perspective. PLoS One 2014; 9: 1-7. doi: 10.1371/journal. pone. 0087322 .

11.- Bedregal P, Besoain C, Reinoso A, Zubarew T. La investigación cualitativa: un aporte para mejorar los servicios de salud. Rev Med Chile 2017; 145: 373-9. http://dx.doi.org/10.4067/ S0034-98872017000300012.

12.- Taylor S, Bogdan R, DeVault M. Introducción ir hacia la gente. Taylor S, Bogdan R y DeVault M. Introduction to Qualitative Research Methods: A Guidebook and Resource, 4th ed. New Jersey: John Wiley \& Sons, Inc.; 2016, p. 15-27.

13.- Hernández R, Fernández C, Baptista P. Capítulo 1: Similitudes y diferencias entre los enfoques cuantitativo y cualitativo. En: Hernández R, Fernández C y Baptista P., eds. Metodología de la Investigación, 5ta ed. México DF: McGraw; 2010, p 2-21.

14.- Fernández M. Diseño de estudios y diseños muestrales en investigación cualitativa. En: Vázquez L, Ferreira M, Mogollón A, Fernández M, Delgado M y Vargas I., eds. Introducción a las técnicas cualitativas de investigación aplicadas en salud, 1ra ed. Barcelona: Servei de Publicacions de la Universitat Autónoma de Barcelona; 2006, p 31-52.

15.- Strauss A, Corbin J. Codificación abierta. En: Strauss A y Corbin J., eds. Bases de la investigación cualitativa. Técnicas y procedimientos para desarrollar la teoría fundamentada, $1^{\text {a }}$ ed. Antioquia: Editorial Universidad de Antioquía; 2002, p. 110-133, 174.

16.- Díaz J. Norma conjunta de prevención de la transmisión vertical del VIH y la sífilis. Programa Nacional de Prevención y Control de la infección por VIH/SIDA e ITS, División de Prevención y Control de Enfermedades, Subsecretaría de Salud Pública, Ministerio de Salud. Rev Chilena Infectol 2013; 30: 259-302. http://dx.doi.org/10.4067/S071610182013000300004.

17.- Villarroel J, Álvarez A, Salvador F, Chávez A, Wu E, Contardo V. Mujeres jóvenes con infección VIH adquirida por transmisión vertical. Expectativas de tener hijos no infectados. Rev Chilena Infectol 2016; 33: 650-5. http://dx.doi.org/10.4067/S071610182016000600006.

18.- INJUV, Ministerio de Desarrollo SocialGobierno de Chile. 8va Encuesta Nacional de la Juventud. INJUV, $2015 \mathrm{http} / / / w w w . i n j u v$. gob.cl/storage/docs/Libro_Octava_Encuesta Nacional_de_Juventud.pdf.

19.- Passerino L. Imaginarios, biomedicina y normatividad: una respuesta a los procesos de estigmatización y discriminación por VIH. Rev Cienc Salud 2013; 11: 217-33. https://revistas. urosario.edu.co/index.php/revsalud/article/ viewFile/2685/2223.

20.- Maskew M, Fox M, Evans D, Govindasamy D, Jamieson L, Malete G, et al. Insights into adherence among a cohort of adolescents aged 12-20 years in South Africa: Reported barriers to antiretroviral treatment. AIDS Research and Treatment 2016; 4161738: 1-12. doi: 10.1155/2016/4161738.

21.- Malanca A, Foradori I, Stankievich E, Pandullo H, Losso M. Disclosure of human immunodeficiency virus diagnosis in children and adolescents affected by it and their caregivers. Arch Argent Pediatr 2017; 115: 195 9.

22.- Adazsko A. Secreto e intimidad entre los adolescentes que crecieron viviendo con VIH/ SIDA desde niños. VII Jornadas de Debate Interdisciplinario de Salud y Población Instituto de Investigación Gino Germani Facultad de Ciencias Sociales, Universidad de Buenos Aires Buenos Aires, 8 al 10 de agosto de 2007 http:// www.cedes.org/publicaciones/documentos/ Salud/2007/7581.pdf.

23.- Wiener L, Mellins CA, Marhefka S, Battles HB. Disclosure of an HiV diagnosis to children: history, current research, and future directions. J Dev Behav Pediatr 2007; 28: 155-66. doi: 10.1097/01.DBP.0000267570.87564.cd. 